\title{
Effects of a Novel Mouthwash on Plaque Presence and Gingival Health
}

\section{Angel Emmanuel Rodriguez and Janet Ajdaharian}

DDS, MSD, 120 South Spalding Drive, Suite 201, Beverly Hills, CA, 90212, USA

*Corresponding author: Angel Emmanuel Rodriguez DDS, MSD, 120 South Spalding Drive, Suite 201, Beverly Hills, CA, 90212, USA, Tel: +49 711 - 4400952; Fax: +49 711 - 633969 78; E-mail: angelrdzp@gmail.com

Received date: October 05, 2017; Accepted date: October 14, 2017; Published date: October 21, 2017

Copyright: @ 2017 Rodriguez AE, et al. This is an open-access article distributed under the terms of the Creative Commons Attribution License, which permits unrestricted use, distribution, and reproduction in any medium, provided the original author and source are credited.

\begin{abstract}
Background: The specific aim of this study was to evaluate the effects of a new mouthwash on plaque and gingival health.

Methods: An in vivo prospective, randomized, controlled, double-blinded study design was used. Ten subjects who had received professional prophylaxis 4-6 weeks prior to study begin abstained from oral hygiene on the lower anterior teeth for 3 days. Baseline measurements including gingival index $(\mathrm{GI})$, plaque index $(\mathrm{PI})$ and bleeding Index $(\mathrm{mSBI})$ were recorded before and afterwards. Participants were randomized with regard to sequence of twice daily 1 min use of a test mouthwash (Oral Essentials ${ }^{\circledR}$ Clean \& Fresh Mouthwash), a control mouthwash (Peridex ${ }^{\mathrm{TM}}$ ) and no mouthwash while abstaining from brushing the lower anterior teeth. GI, PI and $\mathrm{mSBI}$ were recorded before and after each 3-day long arm, with a one week wash out period in between. The effects of each mouthwash on clinical indices were compared using a 2-sided t-test.
\end{abstract}

Results: Test and control mouthwashes produced similar levels of plaque reduction and gingival inflammation $(p>0.05)$ that were significantly better than use of no mouthwash $(p<0.05)$.

Conclusions: A test mouthwash achieved similar effects with regard to plaque control and gingival health as a widely used chlorhexidine mouthwash.

Keywords: Plaque; Gingival inflammation; Oral hygiene; Materials and Methods

\section{Mouthwash}

\section{Introduction}

Periodontal disease affects not only oral health. Recent research has identified potential linkage with systemic conditions such as cardiovascular disease [1-8], diabetes [8], adverse pregnancy outcomes [9], rheumatic arthritis [10], aspiration pneumonia [11] and Chronic Obstructive Airways Disease [11]. It is also being investigated as a potential etiological factor in colorectal cancer [12], oral squamous cell carcinoma [9], pancreatic cancer [13] and breast cancer [14].

Because mechanical plaque removal is arduous, repetitive and timeconsuming, adjuncts such as mouthwashes are welcomed by most individuals [15]. However, studies report widely varying levels of effectiveness with regard to plaque removal, and reported side-effects include altered taste and discoloration [16]. Thus, great interest exists in exploring new formulations and mechanisms for improving plaque control.

The goal of this study was to identify the ability of a test mouthwash (Oral Essentials, Beverly Hills, CA) to reduce plaque presence and improve gingival health. Its effects were compared against those of a control mouthwash (Peridex" ${ }^{\text {"m }}$ ) and the use of no mouthwash at all. Study hypothesis: a test mouthwash will remove plaque and support gingival health equally well as an existing OTC mouthwash [17-21].

\section{Study design}

This was a prospective, randomized, controlled, double-blinded study. All participants provided written informed consent prior to study initiation.

Subjects: Seven female and 3 male subjects were recruited and enrolled in his pilot study. Their ages ranged from 22-38 years old (mean age of 31 years).

\section{Inclusion criteria:}

- Mild to moderate gingival inflammation (Löe and Silness Gingival Index $\geq 2$ ) [22]

- All pocket depths $\leq 5 \mathrm{~mm}$

- Healthy hard and soft tissues based on visual clinical exam

- Professional dental cleaning 4-6 weeks prior to enrollment

\section{Exclusion criteria:}

- Any known allergies to personal care, food or cosmetic consumer products

- Any medical condition which requires pre-medication prior to dental procedures,

- Diminished immune function

- Reported poor wound healing,

- Use of antibiotics within the last 3 months.

- Hepatitis, HIV, ulcer forming diseases, abscesses, granulomas, or severe gingivitis or periodontitis 
- Tobacco use

- Pregnant

- Lactating

\section{Clinical protocol}

Ten subjects who had received professional prophylaxis within 4-6 weeks of study begin abstained from oral hygiene on the lower anterior teeth for 3 days. Plaque levels (Turesky Modification of Quigley-Hein Index [23] (PI), gingival inflammation (Löe and Silness Gingival Index [22] (GI), and sulcus bleeding (mSBI) [24] were recorded before and after cessation of oral hygiene measures (please see below for details). Next, participants were randomized with regard to sequence of twice daily $1 \mathrm{~min}$ use of a test mouthwash, a control mouthwash and no mouthwash while abstaining from brushing the lower anterior teeth. GI, PI and mSBI were recorded before and after each 3-day long arm. During the one week wash out period between each study arm, subjects brushed with Crest ${ }^{\circ}$ Pro-Health ${ }^{\text {pw }}$ toothpaste (Procter and Gamble, Cincinnati, OH) using a new Oral $\mathrm{B}^{\circ}$ Pro-Flex ${ }^{\mathrm{mt}}$ toothbrush (Procter and Gamble, Cincinnati, $\mathrm{OH}$ ) for each washout period of the study. Use of any other oral hygiene measures was not permitted, included chewing gum. At each visit this information was repeated to the subjects and a written information sheet was also sent home with them after each visit.

One independent study manager uniquely had access to the key for the sample codes. Otherwise, all investigators and subjects were blinded with regard to the mouthwash allocation. At each visit, subjects were questioned about any potential adverse effects of any products. 24-hour telephone contact information was provided to all subjects in case of any emergencies.

\section{Indices}

Plaque was scored on a scale of 0 to 5 according to the Turesky modification of the Quigley-Hein Plaque Index [23]. Gingival health was evaluated using the Löe-Silness Gingival Index (0-3) [22] and the Sulcus Bleeding Index [24].

\section{Data analysis}

I order to evaluate the data, the difference between endpoint and baseline value for each parameter was determined for each subject. Using a 2-sided T-test and standard statistical approach for crossover studies [25], the clinical indices at study end were compared between (a) test and control mouthwash and (b) test mouthwash vs no mouthwash.

\section{Results}

At study outset and after 3 days of abstaining from oral hygiene, the clinical indices did not differ significantly between all subjects (Figures 1-3). None of the data showed any evidence of a significant carryover effect from the first arm to the second ( $p>0.186)$. For all of the clinical indices measured, the test mouthwash effects did not differ significantly from those of the control mouthwash $(p>0.164)$. Both mouthwashes removed plaque and maintained gingival health more effectively than when no mouthwash was used $(\mathrm{p}<0.05)$.

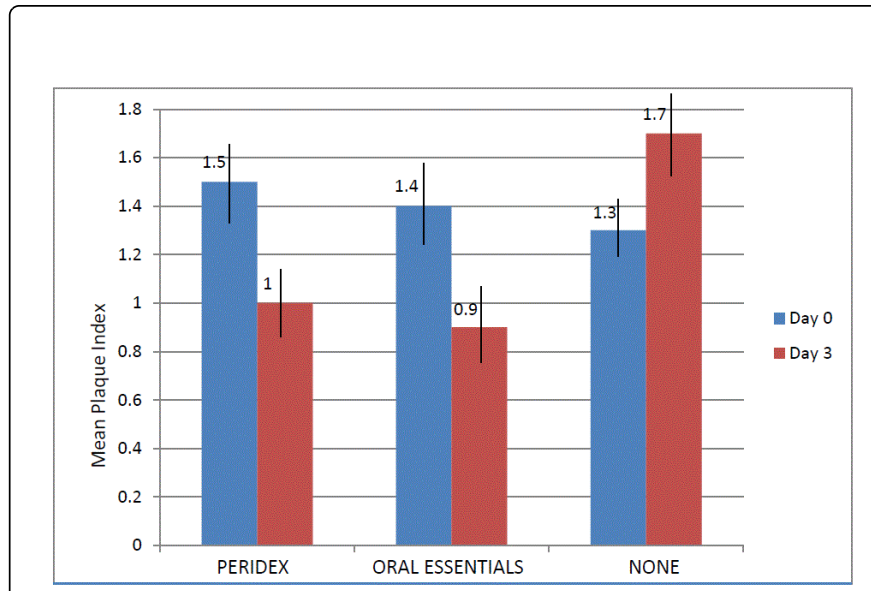

Figure 1: Mean Plaque Index (SD) before and after 3 days of Peridex ${ }^{\text {w* }}$, Oral Essentials, or No Mouthwash.

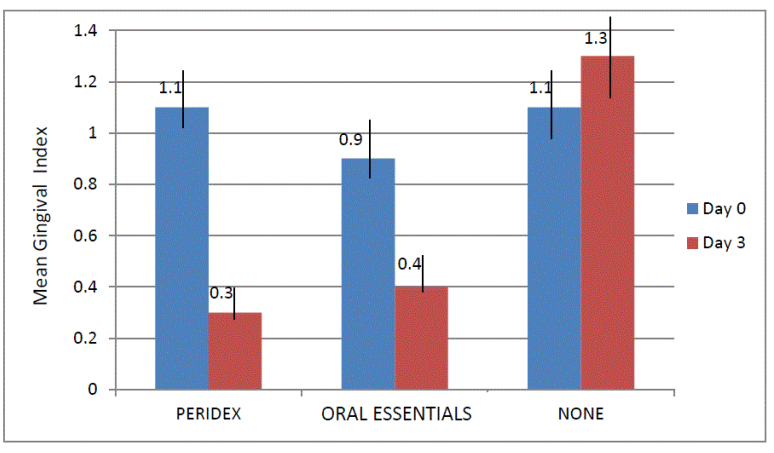

Figure 2: Mean Gingival Index (SD) before and after 3 days of Peridex ${ }^{m}$, Oral Essentials, or No Mouthwash.

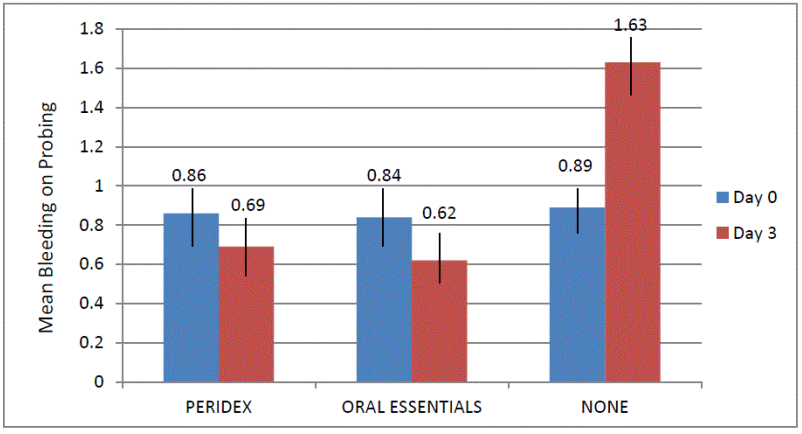

Figure 3: Mean Bleeding on Probing (SD) before and after 3 days of Peridex ", Oral Essentials, or No Mouthwash.

\section{Discussion}

Goal of this in vivo study was to compare the level of plaque control and clinical gingivitis after the use of a test mouthwash vs a control 
mouthwash and use of no mouthwash at all. A professional prophylaxis was performed 4-6 weeks prior to enrollment to remove calculus and allow for gingival healing.

The crossover study design that was used in this research is valid where there are minimal carry over effects [26,27]. Our data confirm that this was indeed the case in this study. In order to further overcome any potential effects of the sequential crossover design of this study, the sequence of mouthwash usage was randomized so that 3 subjects used the test mouthwash first, 3 subjects used the control mouthwash first, and 4 subjects used no mouthwash at all first [28]. Overall, during the 8 -week study period, oral health improved in both groups using the mouthwash [29-35].

Three-day use of the test or the control mouthwash reduced plaque presence and gingival inflammation to a very similar degree. Plaque indices were reduced by approximately 30\% after 3-day use of either mouthwash, whereas plaque levels increased by approx. $25 \%$ when no mouthwash was used. Gingival indices and BOP were significantly reduced after use of either mouthwash, whereas they increased significantly in the absence of a mouthwash régimen [36-48].

Mechanical plaque control has limited effectiveness in ensuring oral health. For this reason there exists considerable interest in alternative or adjunct approaches to existing mechanical oral hygiene techniques. For example, chlorhexidine provides for excellent short-term plaque control and concomitant improvement in gingival health. However, its use is limited due to some of its side effects that include tooth staining and taste alterations after longer usage [49]. Moreover, unlike the test product, chlorhexidine has been shown ex vivo to have a cytotoxic effect on cells [50]. Because of the pressing need for additional options, a wide range of active components is under investigation as possible alternatives to chlorhexidine. The novel plaque-control mouthwash formulation used in this study may provide a useful adjunct for plaque control means of overcoming the shortcomings of existing mechanical and chemical methods of plaque control.

\section{Conclusion}

In this clinical pilot study, a test mouthwash demonstrated comparable levels of plaque control and reduction in gingival inflammation over 3 days to a commonly used chlorhexidine-based mouthwash. Further studies in greater numbers of subjects are required to evaluate the effectiveness of the test mouthwash over longer periods and to identify ideal usage regimens.

\section{Conflict of Interest Statement}

No conflict of interest

\section{Author Contributions Statement}

\section{Angel Emmanuel Rodriguez}

Concept/Design, data collection, drafting article, final approval.

\section{Janet Ajdaharian}

Concept/Design, data collection, drafting article.

\section{Acknowledgement}

This research was supported by Oral Essentials Inc.

\section{References}

1. Tonetti MS, Eickholz P (2015) Principles in prevention of periodontal diseases: Consensus report of group 1 of the 11th European Workshop on Periodontology on effective prevention of periodontal and peri-implant diseases. J Clin Periodontol 42: 5-11.

2. Eke PI, Dye BA, Wei L, Thornton-Evans GO, Genco RJ (2010) Prevalence of periodontitis in adults in the United States: 2009 and 2010. J Dent Res 91: 914-920.

3. Di Benedetto A, Gigante I, Colucci S, Grano M (2013) Periodontal disease: linking the primary inflammation to bone loss. Clin Dev Immunol 2013:1-7.

4. Marsh PD (2006) Dental plaque as a biofilm and a microbial community - implications for health and disease. BMC Oral Health 6: 14.

5. Genco RJ, Borgnakke WS (2000) Risk factors for periodontal disease. Periodontology 62: 59-94.

6. Kim J, Amar S (2006) Periodontal disease and systemic conditions: a bidirectional relationship. Odontology 94: 10-21.

7. Cullinan MP, Ford PJ, Seymour GJ (2009) Periodontal disease and systemic health: current status. Aust Dent J 54: 62-69.

8. Thomas RZ, Loos BG, Teeuw W, Kunnen A, Van Winkelhoff AJ, et al (2015) Periodontitis and systemic diseases: from science to clinical practice. Ned Tijdschr Tandheelkd 122: 542-548

9. Han YW, Houcken W, Loos BG, Schenkein HA, Tezal M (2014) Periodontal disease, atherosclerosis, adverse pregnancy outcomes, and head-and-neck cancer. Adv Dent Res 26: 47-55.

10. Hashimoto M, Yamazaki T, Hamaguchi M, Morimoto T, Yamori M, et al. (2015) Periodontitis and Porphyromonas gingivalis inpreclinical stage of arthritis patients. PLoS One 10: e0122121.

11. Bansal M, Khatri M, Taneja V (2013) Potential role of periodontal infection in respiratory diseases - a review. J Med Life 6: 244-248.

12. Castellarin M, Warren RL, Freeman JD, Dreolini L, Krzywinski M, et al. (2012) Fusobacterium nucleatum infection is prevalent in human colorectal carcinoma. Genome Res 22: 299-306.

13. Taguchi A (2007) Re: A prospective study of periodontal disease and pancreatic cancer in US male health professionals. J Natl Cancer Inst 99: 738-739.

14. Freudenheim JL, Genco RJ, LaMonte MJU (2016) Periodontal Disease and Breast Cancer: Prospective Cohort Study of Postmenopausal Women. Cancer Epidemiol Biomarkers Prev 25: 43-50.

15. Van der Weijden GA, Hioe KP (2005) A systematic review of the effectiveness of self-performed mechanical plaque removal in adults with gingivitis using a manual toothbrush. J Clin Periodontol 32: 214-228.

16. Gunsolley JC (2006) A meta-analysis of six-month studies of antiplaque and antigingivitis agents. J Am Dent Assoc 137: 1649-1657.

17. Carranza FA, Takei H, Newman MG, Klokkevold PR (2012) Clinical Periodontology, St. Louis, Elsevier Saunders: Missouri, USA.

18. Donlan RM, Costerton JW (2002) Biofilms: Survival Mechanisms of Clinically Relevant Microorganisms. Clin Microbiol Rev 15: 167-193.

19. Lam T, Zadmehr S, Khashai F, Saikaly V, Sahni K, et al. (2016) Effects of Toothpaste on Surface Enamel: An In Vivo Imaging Study. J Dent Res 95 : $04-43$

20. Sabokpey S, Biren-Fetz J, Dadkhah M, Liaw LH, Wilder-Smith P (2013) In vivo study of the effects of a novel dental gel on enamel remineralization after acid erosion, 33rd American Society for Laser Medicine and Surgery Annual Conference, Boston, MA, April 3-7.

21. Lam T, Ho J, Anbarani AG, Liaw L-H, Takesh T, et al. (2016) Effects of a Novel Dental Gel on Enamel Surface Recovery from Acid Challenge. 6.

22. Löe H (1967) The Gingival Index, the Plaque Index and the Retention Index Systems. J Periodontol 38: 610-616.

23. Turesky S, Gilmore ND, Glickman I (1970) Reduced plaque formation by the chloromethyl analogue of victamine C. J Periodontol 41: 41-43.

24. Newbrun E (1996) Indices to measure gingival bleeding. J Periodontol 67: $555-561$ 
25. Wellek S, Blettner M (2012) On the proper use of the crossover design in clinical trials: part 18 of a series on evaluation of scientific publications. Dtsch Arztebl Int 109: 276-285.

26. Feil PH, Grauer JS, Gadbury-Amyot CC, Kula K, McCunniff MD (2002) Intentional use of the Hawthorne effect to improve oral hygiene compliance in orthodontic patients. J Dent Educ 66: 1129-1135.

27. Suresh K (2011) An overview of randomization techniques: An unbiased assessment of outcome in clinical research. J Hum Reprod Sci 4: 8-11.

28. Prasanth M (2011) Antimicrobial Efficacy of Different Toothpastes and Mouthrinses: An In Vitro Study. J Dent Res 8: 85-94.

29. Yazdankhah SP, Scheie AA, Høiby EA, Lunestad BT, Heir E, et al. (2006) Triclosan and antimicrobial resistance in bacteria: an overview. Microb Drug Resist 12: 83-90.

30. Loesche WJ, Grossman NS (2001) Periodontal Disease as a Specific, albeit Chronic, Infection: Diagnosis and Treatment. Clin Microbiol Rev 14 727-752.

31. Davies RM, Ellwood RP, Davies GM (2004) The effectiveness of a toothpaste containing Triclosan and polyvinyl-methyl ether maleic acid copolymer in improving plaque control and gingival health. J Clin Periodont 31: 1029-1033.

32. Jenkins S, Addy M, Newcombe RG (1994) Dose response of chlorhexidine against plaque and comparison with triclosan. J Clin Periodont 21: 250-255.

33. Palomo F, Wantland L, Sanchez A, Volpe AR, McCool J, et al. (1994) The effect of three commercially available dentifrices containing triclosan on supragingival plaque formation and gingivitis: a six month clinical study. Int Dent J 44: 75-81.

34. Dadkhah M, Chung NE, Ajdaharian J, Wink C, Klokkevold P (2014) Effects of a Novel Dental Gel on Plaque and Gingivitis: A Comparative Study. Dentistry 4: 239-246.

35. Chung ME, Dadkhah M, Sarraf A, Kohanchi D, Chan G, et al. (2013) An imaging-based approach to evaluating dentifrice. 33rd American Society for Laser Medicine and Surgery Annual Conference, Boston, MA, April 3-7.

36. Sabokpey S, Biren-Fetz J, Wink C, Wilder-Smith P (2014) Imaging in vivo the effects of dentifrices on oral biofilm. 43rd Annual Meeting of the American Association for Dental Research, Charlotte, NC, March 19-22.

37. Sabokpey S, Biren-Fetz J, Krasieva TB, Dadkhah M, Chung NE, et al. (2014) Optical approach to evaluating the effects of a novel dental gel on oral biofilm. 34th American Society for Laser Medicine and Surgery Annual Conference, Phoenix, AZ, April 2-6.
38. Sahni K, Krasieva T, Ho J, Ngo W, Saikaly V, et al. (2015) Mapping the effectiveness of anti-plaque treatments. 35th American Society for Laser Medicine and Surgery Annual Conference, Kissimmee, FL, April 22-26.

39. Ajdaharian J, Dadkhah M, Sarraf A, Kohanchi D, Chan G, et al. (2013) Imaging gingivitis response to a novel dentifrice. 33rd American Society for Laser Medicine and Surgery Annual Conference, Boston, MA, April 3-7.

40. Ajdaharian J, Dadkhah M, Sabokpey S, Biren-Fetz J, Chung NE, et al. (2014) Multimodality imaging of the effects of a novel dentifrice on oral biofilm. Lasers Surg Med 46: 546-552.

41. Chang Y, Gu W, McLandsborough L (2012) Low concentration of ethylenediaminetetraacetic acid (EDTA) affects biofilm formation of Listeria monocytogenes by inhibiting its initial adherence. Food Microbiol 29: 10-17.

42. Bryce G, O'Donnell D, Ready D, Ng YL, Pratten J, et al. (2009) Contemporary root canal irrigants are able to disrupt and eradicate single- and dual-species biofilms. J Endod 35: 1243-1248.

43. Zhang M, Wong IG, Gin JB, Ansari NH (2009) Assessment of methyl sulfonylmethane as a permeability enhancer for regional EDTA chelation therapy. Drug Deliv 16: 243-248.

44. Aut SA, Angus RA (2010) Triclosan has endocrine-disrupting effects in male western mosquitofish, Gambusia affinis. Environ Toxicol Chem 29: 1287-1291.

45. Hioe KP, Van der Weijden GA (2005) The effectiveness of self-performed mechanical plaque control with triclosan containing dentifrices. Int J Dent Hyg 3: 192-204.

46. Scattarella A, Petruzzi M, Ballini A, Grassi F, Nardi G (2011) Oral lichen planus and dental hygiene: a case report. Int J Dent Hyg 9: 163-166.

47. De Menezes M, Turssi CP, Hara AT, Messias DC, Serra MC (2004) Abrasion of eroded root dentine brushed with different toothpastes. Clin Oral Investig 8: 151-155.

48. Shumaker ND, Metcalf BT, Toscano NT, Holtzclaw DJ (2009) Periodontal and periimplant maintenance: a critical factor in long-term treatment success. Compend Contin Educ Dent 30: 388-390.

49. Eriksen HM, Nordbø H, Kantanen H, Ellingsen JE (1985) Chemical plaque control and extrinsic tooth discoloration. A review of possible mechanisms. J Clin Periodontol 12: 345-350.

50. Huang FM1, Li YC, Lee SS, Chang YC (2010) Cytotoxicity of chlorhexidine on human osteoblastic cells is related to intracellular glutathione levels. Int Endod J 43: 430-435. 